\title{
Artelogie
}

Recherche sur les arts, le patrimoine et la littérature de l'Amérique latine

$10 \mid 2017$

Après le paysage : l'art, l'inscription et la représentation de la nature en Amérique latine aujourd'hui

\section{Um museu ausente: curadoria contemporânea e ativismo indigenista}

A Queda do Céu, Sao Paulo, 2015; Adornos do Brasil Indígena, Pinheiros, 2016

\section{Gabriel Bogossian}

\section{OpenEdition}

\section{Journals}

Edição electrónica

URL: http://journals.openedition.org/artelogie/882

DOI: $10.4000 /$ artelogie. 882

ISSN: 2115-6395

\section{Editora}

Association ESCAL

\section{Refêrencia eletrónica}

Gabriel Bogossian, «Um museu ausente: curadoria contemporânea e ativismo indigenista », Artelogie [Online], 10 | 2017, posto online no dia 05 abril 2017, consultado o 20 abril 2019. URL : http:// journals.openedition.org/artelogie/882 ; DOI : 10.4000/artelogie.882

Este documento foi criado de forma automática no dia 20 Abril 2019.

Association ESCAL 


\section{Um museu ausente: curadoria contemporânea e ativismo indigenista}

A Queda do Céu, Sao Paulo, 2015; Adornos do Brasil Indígena, Pinheiros, 2016

\section{Gabriel Bogossian}

1 Embora com atuação restrita a eventos nacionais e regionais, o curador pernambucano Moacir dos Anjos ocupa, no cenário artístico brasileiro, um lugar de destaque. Largamente fundada nos estudos pós-coloniais e definida pelo próprio dos Anjos como o exercício de uma curadoria menor - noção de literatura menor, que Deleuze e Guattari desenvolveram em seu famoso ensaio sobre a obra de Kafka -, sua prática curatorial busca produzir enunciados de um lugar positivamente subalterno, no qual as consequências de uma modernidade conturbada e tardia ditariam os parâmetros do debate cultural hoje.

2 Estratégia de resistência possível, segundo dos Anjos, sua curadoria menor age ao lado de uma produção simbólica também minoritária, que opera no sentido de desalojar "a arte maior de suas convicções, tornando-a crescentemente impura e hesitante". Em que pesem as limitações do lugar de fala curatorial - que transita entre discursos institucionais, artísticos, mercadológicos, etc., a fim de elaborar um pensamento poético baseado na (e sustentado pela) instabilidade desse trânsito - e a própria insuficiência do campo da arte frente a um contexto cultural que impõe sucessivas derrotas à sua ambição de proporcionar experiências simbólicas relevantes (ou mesmo desejáveis), Moacir dos Anjos vem desenvolvendo nos últimos dez anos uma consistente articulação crítica entre disputas políticas e a produção artística contemporânea brasileira.

3 A Queda do Céu (2015) e Adornos do Brasil Indígena - Resistências contemporâneas (2016), duas de suas exposições mais recentes, tomam partido dessa perspectiva minoritária para investigar o que se convencionou chamar "a questão indígena" no Brasil. É necessário, no entanto, considerá-las em diálogo, a fim de assinalar que fatos novos foram produzidos no 
que se refere às aproximações entre disputas políticas e disputas simbólicas no cenário brasileiro, em particular aquelas envolvendo os direitos indígenas.

4 Inauguradas com apenas 13 meses de diferença, as duas exposições pretendem dar a ver o estado da arte da questão indígena; abordam, portanto, as violentas disputas territoriais e o impressionante silêncio - revelador de uma ignorância profunda, ou ainda uma falta de empatia - que pesa sobre os povos indígenas no Brasil. Trazem também ensaios de resistência, alguns registros cotidianos e outros dramáticos, de disputas políticas, como as obras de Jimmie Durham, artista de origem Cherokee, e o discurso de Aílton Krenak, intelectual e político Krenak, durante a Assembleia Nacional Constituinte, em 1987. Não à toa, o discurso de Krenak é a única peça que se repete nas duas exposições.

5 Completando os conjuntos de obras contemporâneas, em A Queda do Céu há ainda seis desenhos produzidos por autores yanomami, integrantes de coleções particulares e "coletados" em campo. Adornos do Brasil Indígena, realizada em parceria com o Museu de Arqueologia e Etnologia da USP, o lugar do Outro é ocupado por um conjunto etnográfico vindo da coleção do Museu: cerâmicas, plumária, máscaras e outros objetos, representando 23 diferentes povos.

6 Em um texto de junho de 2016, Moacir dos Anjos defende a necessidade de uma "arte índia", "que seja afetada por uma guerra de ocupação que está longe de ser terminada e que dela participe, com solidariedade e empatia, a partir de suas próprias capacidades." A produção de artistas do sistema da arte, nas duas exposições, reúne nomes que, no entender de dos Anjos, dariam conta de continuar o relato do contato entre indígenas e não-indígenas; artistas cujas obras dão, portanto, testemunho do encontro com o Outro, articulando sua existência a uma visão sobre o mundo.

7 Embora louváveis, de um ponto de vista artístico, as duas exposições foram concebidas a partir das premissas desse campo; sofrem, portanto, das limitações de seu funcionamento. Considerada à luz de um pensamento que busca intervir na construção das narrativas históricas da arte brasileira, complexificando seus discursos, é possível indicar lacunas importantes na fala curatorial de Moacir dos Anjos. Nas duas exposições, a ausência de perspectiva histórica que situe as disputas reais de povos diversos no universo amplo das narrativas nacionais - sobre o desenvolvimento econômico, é claro, mas também cultural, sobretudo no que diz respeito à ideia de mestiçagem - limita a desejada articulação entre discurso contemporâneo e ativismo. A co-presença de objetos etnográficos e objetos artísticos, em Adornos, e o positivo deslocamento semântico das duas categorias promovido por esse artifício - instrumentos de uma curadoria menor que tensiona de modo ativo diferentes campos do conhecimento - não foi capaz de estabelecer uma continuidade discursiva entre eles, uma vez que os objetos etnográficos na exposição não guardam relação clara com os eixos conceituais que estruturam a mostra. Essa descontinuidade fica mais clara quando tomamos o texto do catálogo de Adornos e sua tentativa de aproximação das duas classes de objetos. Dos Anjos se serve de uma ideia de beleza a-histórica, descolada de qualquer outro saber - indígena ou não - sobre os objetos em cena. Nessa exposição, o questionamento da ideia de mestiçagem, central para a percepção da "questão indígena" pelo público maior - já que ela situa a diferença no passado, onde teria sido resolvida -, não ocorre senão indiretamente, por sugestão; o avizinhamento, no espaço expositivo, de diferentes frutos do contato entre indígenas e não indígenas não chega a desarticular o cânone, pois ele não está ali - ou está, pairando como entidade negativa, no nível ideológico. No mesmo sentido, os desenhos yanomami incluídos em A Queda do Céu carecem dos anteparos discursivos - crítico, etnográfico, 
histórico, não importa - que reduziria nossa defasagem perceptiva dessas imagens. Não existe nessas mostras, sobretudo, uma autocrítica do campo da arte (recurso utilizado por dos Anjos em outras exposições), que permita ao menos o surgimento da dúvida sobre os limites do campo. Articulada de maneiras menos sofisticadas que as "obras de arte" de $A$ Queda do Céu e Adornos do Brasil Indígena, a presença indígena nessas exposições parece enfim ilustrar um desejo de aproximação, ainda por se realizar.

8 Tomadas a partir da "guerra de ocupação" em curso, o clarão benjaminiano que as duas exposições instauram é tênue, portanto. E se no atual cenário de trevas faz com que essa luz breve se destaque, é preciso reconhecer que, no campo artístico, o contato não produziu um bom encontro; gaguejamos ainda em busca das palavras certas.

\section{ANEXOS}

Anna Bella Geiger, série Història do Brasil - Little Boys and Girls, 1975

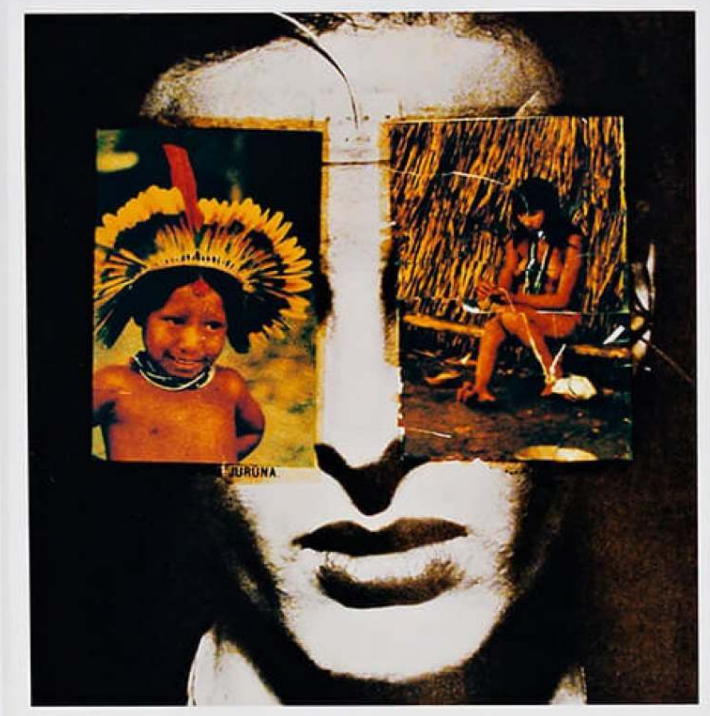

(c) Collection de l'artiste, courtesy of Henrique Faria Fine Arts, New York, Copyright de l'artiste, 1975, Exposition America Latina 1960-2013, Fondation Cartier pour l'art contemporain, Paris 
Ailton Krenak na Assembleia Nacional Constituinte de 1987

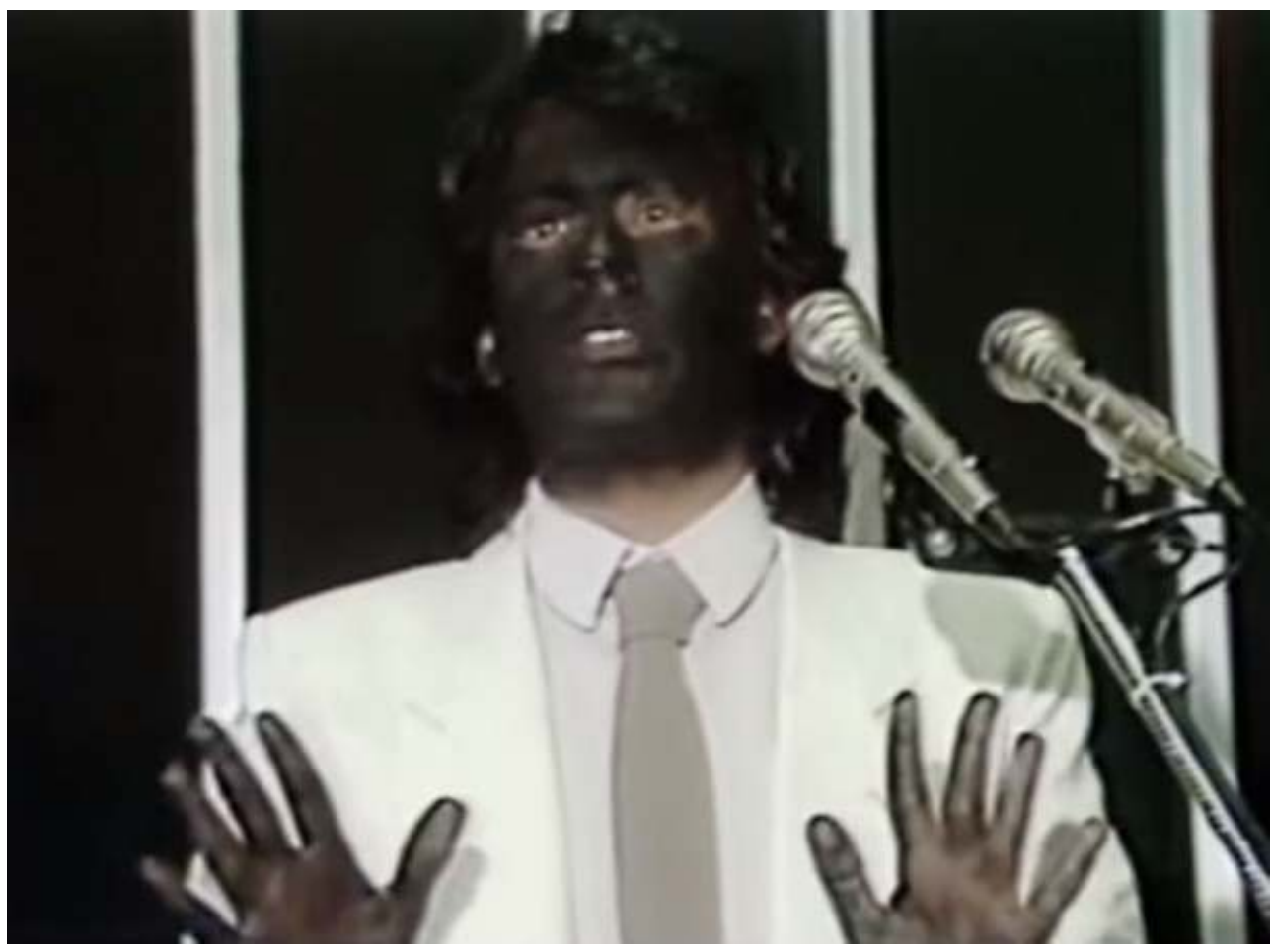

Foto: Reprodução YouTube

Claudia Andujar, A Queda Do Ceu

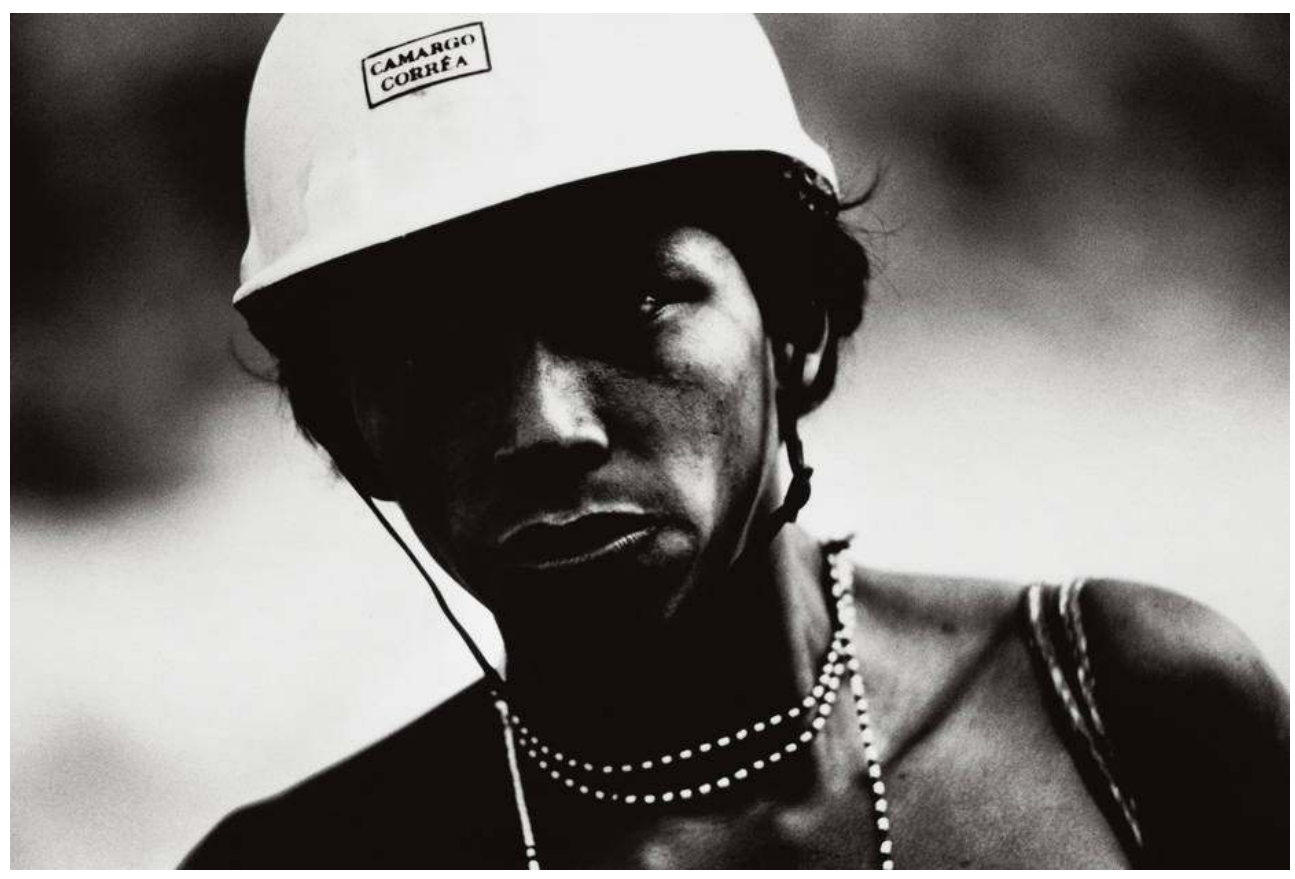


Cildo Meirelles, Zero Real

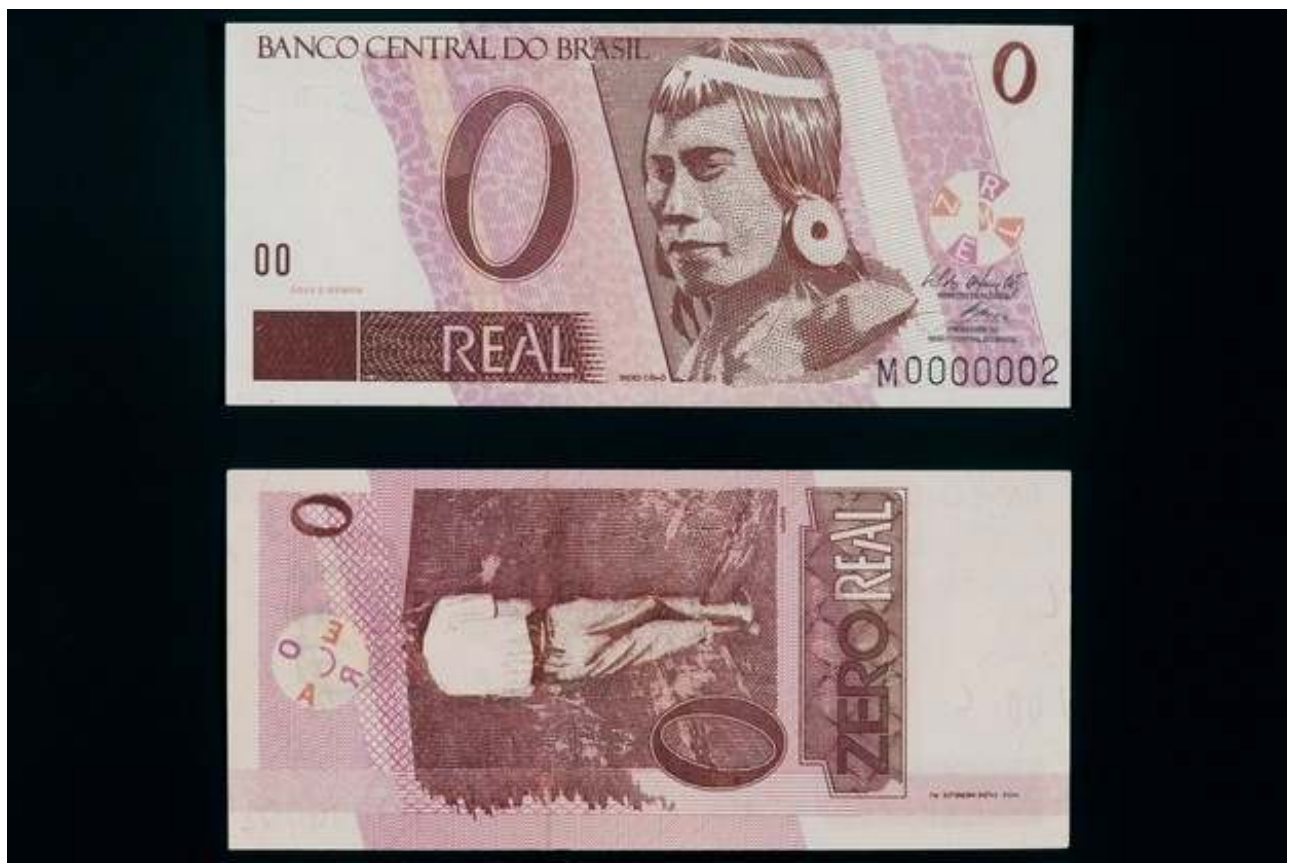

Créditos: Pat Kilgore / Créditos (capa): Carolina Ferreira

\section{AUTOR}

\section{GABRIEL BOGOSSIAN}

Curador independiente 